\title{
Wie Legastheniker besser Lesen lernen
}

\section{Kindern mit einer Lese-Rechtschreib- Schwäche (Legasthenie) kann bisher nur mit relativ aufwendigen Trainings- programmen geholfen werden. Um die verbesserte Leseleistung aufrecht zu erhalten, müssen die Kinder zu- sätzlich viel lesen - was meist an der Dyslexie scheitert. Italienische Forscher haben jetzt eine Methode gefunden, mit der sich die Leseleis- tung der Legastheniker ohne lange Vorbereitung sofort signifikant ver- bessern lässt.}

— Für ihre Studie führten die Forscher der Universität Padua Tests mit 74 legasthenischen Kindern im Alter von 4 bis 18 Jahren durch. Eine Hälfte der Kinder stammte aus Italien, die andere aus Frankreich.

Die Kinder erhielten jeweils ein Blatt mit 24 kurzen Sätzen in ihrer Muttersprache. Sie sollten sie laut vorlesen. In einem Test waren diese Sätze mit normalem Buchstaben- und Zeilenabstand gedruckt. Im zweiten Test waren Buchstaben- und Zeilenabstand verdoppelt, die Wörter waren durch jeweils drei Leerzeichen statt nur einem voneinander getrennt.

Die legasthenischen Kinder machten beim Lesen der weiter gesetzten Textversion 50\% weniger Fehler. Bei den französischen Kindern erhöhte sich auch die Lesegeschwindigkeit um 20\%. Im Französischen stimmen ja - anders als im Italienischen - Schreibweise und Aussprache nicht überein. Der Fortschritt in der Leseleistung, den Kinder durch den weiter gesetzten Text erzielten, entspricht in etwa dem Fortschritt, den Grundschüler in einem Schuljahr zeigen.

Je schlechter es den Kindern gelang, die Buchstaben beim normal gesetzten Text korrekt zu erkennen, umso mehr profitierten sie vom erweiterten Buchstabenabstand. Nicht-Legastheniker zeigten diese positiven Effekte nicht. Sie schnitten mit dem weiter gesetzten Text eher schlechter ab als mit dem normal formatierten.

\section{Kommentar}

Die Forscher führen die positiven Effekte auf die Verringerung des sogenannten Crowding-Effekts zurück. Legastheniker haben Probleme, benachbarte Buchstaben visuell zu trennen. Diese Störeffekte führen zu Lesefehlern und verlangsamen das Lesetempo. Der weite Buchstabenabstand verringert diesen Effekt.

K. MALBERG =

- Zorci, M et al.

Extra-large letter spacing improves reading in dyslexia. Published online in Proc Soc Natl Acad Sci, 2012

\section{Pneumoperitoneum}

\section{Darmperforation?}

— Eine 69-jährige Frau wurde wegen seit drei Tagen bestehenden zunehmenden Bauchschmerzen und gespannten Bauchdecken in die Nothilfe eingeliefert. Sie stand unter Dexamethason zur Behandlung eines Hirnödems im Zusammenhang mit einem Glioblastoma multiforme.

Die Patientin war kachektisch, sie atmete hochfrequent und flach, die Bauchdecken waren gespannt, es bestanden ein diffuser Druck-, aber kein Loslassschmerz oder anderweitige Zeichen einer Peritonitis. Die Thoraxaufnahme in zwei Ebenen zeigte ein Pneumoperitoneum mit einer Ausdehnung der Luft von der Zwerchfellkuppel bis zum Leberunterrand, wodurch sich die Gallenblase besonders gut darstellte (Abb. A, Pfeil). Durch die Luftfüllung kontrastierte auch die Milz auf der seitlichen Aufnahme
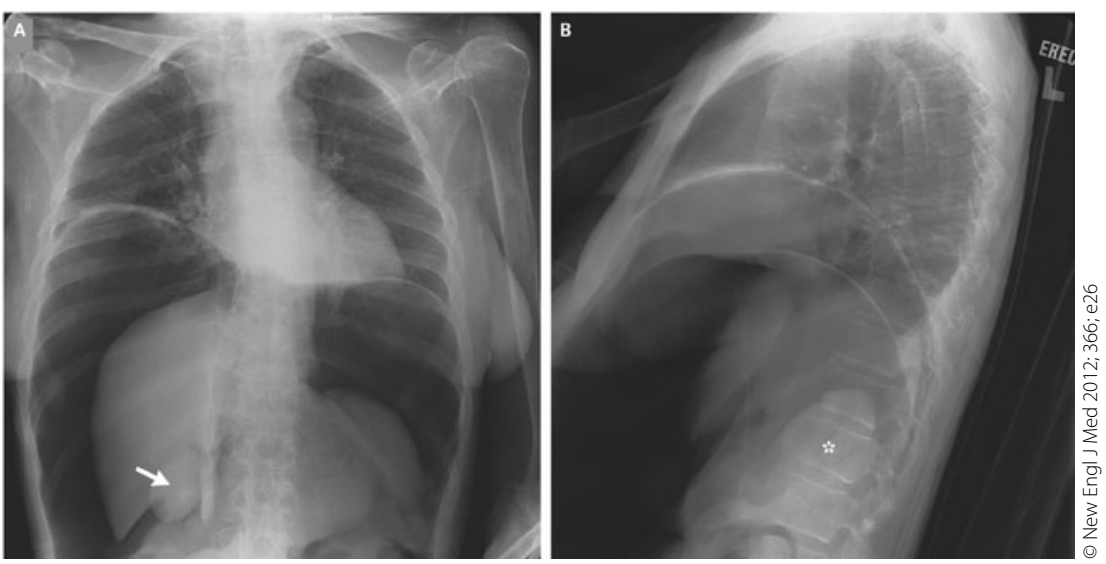

Pneumoperitoneum: Gallenblase (A; Pfeil) und Milz (B; Stern) sind gut zu erkennen.

(Abb. B, $\left.{ }^{\star}\right)$. Die Befunde waren hoch verdächtig für eine Darmperforation. Wegen der Grunderkrankung der Patientin entschloss man sich lediglich zu Palliativmaßnahmen, zumal auch eine Patientenverfügung vorlag. Kurz nach einer Entlastungspunktion zur Dekompression des Abdomens verstarb die Patientin.

H. S. FÜESSL -

- J. Ailon

Pneumoperitoneum. New Engl J Med 2012; 366; e26 